\title{
Una mirada sobre la educación superior en América Latina
}

A look at higher education in

Latin America

\author{
Martín Unzué \\ Director del Instituto de Investigaciones Gino Germani \\ Facultad de Ciencias Sociales \\ Universidad de Buenos Aires \\ E-mail: unzuemart@yahoo.com
}

La expansión de la educación superior, y dentro de ella de la universitaria ${ }^{1}$, ha resultado tradicionalmente un indicador relevante de desarrollo social. A pesar de esto los datos agregados referidos a la región Latinoamericana, conservando su heterogeneidad, permiten constatar que ya hace varias décadas que se está produciendo un proceso de expansión del nivel superior, que ha sido muy significativo al menos en el último cuarto de siglo.

La cantidad de estudiantes de Instituciones de Educación Superior (IES) casi se ha duplicado en lo que va del siglo XXI (BM, 2017), con algunos países mostrando niveles de acceso a las IES de los graduados de las escuelas secundarias, muy elevados, como Uruguay con un 80\%, o Argentina y México con números en torno al 65\%.

Sin dudas cuestiones preliminares como el avance de los niveles iniciales de educación y particularmente de la educación media, juegan un papel importante en este desarrollo, pues son condición necesaria para que suceda, aunque no suficiente. El paso del nivel medio al superior presenta una serie de complejidades, que deben ser tramitadas de modos diversos para poder lograr resultados exitosos. En este punto, podemos encontrar aspectos

\footnotetext{
${ }^{1}$ Notemos que la formación superior se divide en educación universitaria y no universitaria (terciaria). En varios casos, como en Argentina, existe una única ley que regula el funcionamiento de toda la educación superior (ley de Educación Superior 24.521), pero estableciendo las diferencias entre ambos subsectores. Los estudios terciarios se realizan en instituciones que no son universidades, y suelen tener duraciones temporales menores que las carreras universitarias. Las universidades por su parte, incluidos los institutos universitarios, tienen entre sus tareas promover y desarrollar la investigación científica, tecnológica, humanística y la creación artística.
} 
vinculados a la educación media, que hacen a la calidad de la misma, y a sus estrategias de construcción de la transición a niveles superiores, que son relevantes para consolidar esa continuidad de los estudios. También debemos hacer referencia a toda una serie de elementos propios del nivel superior para explicar esta expansión.

La disponibilidad de instituciones, su distribución territorial, la inversión realizada en ellas, los mecanismos para favorecer el acceso de los sectores de menores recursos son todos elementos relevantes para analizar este crecimiento.

En primer lugar, porque la evidencia parece asociar el desarrollo del sector con la inversión que se produce en el mismo, y aquí encontramos situaciones muy diversas. En algunos casos es el sector público el que realiza los mayores esfuerzos para el sostenimiento de las IES (como sucede en México, Argentina, o Panamá por citar algunos casos), mientras en otros países de la región esto queda en manos predominantemente del sector privado sea o no con fines de lucro, aunque esa dimensión privada ya parece señalar que hay una restricción económica que debe ser saldada (son ejemplos de ello Chile, Colombia, o Guatemala). En estos casos, para que eventuales aranceles no se constituyan en un límite infranqueable para el acceso de sectores numerosos de la población, se requieren políticas específicas de subsidio a los potenciales estudiantes necesitados o a las instituciones, vía políticas afirmativas de cuotas.

Estos datos se deben vincular con la proporción de IES públicas y privadas, que tiene como casos extremos a Uruguay, Bolivia y Argentina con la mayor participación estatal, frente a Chile, Brasil o El Salvador, donde encontramos un predominio de instituciones privadas.

Hay un tercer elemento relevante, que suele ser desconsiderado por buena parte de las estadísticas, y es la relación entre el sistema de educación superior y el subsistema universitario. En general, en muchos de los países, predominan las IES no universitarias, tanto en número de instituciones, lo que resulta lógico, como en cantidad de estudiantes que reciben.

En este punto casos como los de Uruguay o Argentina se caracterizan por el predominio de las instituciones universitarias, muy diferente a lo que sucede en otros como Brasil o Colombia, donde son las instituciones terciarias las que captan la mayor parte de los estudiantes del nivel superior. 
Esto quiere decir que cuando se hacen consideraciones generales sobre el avance de la educación superior en América Latina, hay algunas dimensiones que resultan importantes para ver la heterogeneidad entre los países, empezando por la relación entre el subsistema público y el privado, y luego entre el universitario y el no universitario.

Estas distinciones tienen implicancias diversas sobre el tipo de estudios que se ofrecen, pero también, sobre la calidad de los mismos, sin dudas un indicador fundamental a ser considerado. El mero acceso al nivel superior, o el crecimiento de la educación superior en la región, puede tener consecuencias muy diversas en términos de desarrollo, nivel de formación, tipo y calidad de los recursos humanos, o incluso, en la interrupción de las relaciones O-D, y el dato sobre los tipos de institución y su calidad resultan fundamentales.

Luego vienen las consideraciones sobre las tasas de graduación o el problema del abandono, que es importante notar que suele ser elevado en la región, así como la inversión total en el sistema, o por estudiante, o por graduado, los salarios de los profesores, la incidencia del egreso de este nivel sobre los niveles salariales esperables, entre otros indicadores.

Evidentemente, una educación superior de calidad, al alcance de todos los sectores con independencia de sus niveles iniciales o familiares de ingresos o trayectorias educativas, y que sea coronada con la graduación, debería ser el ideal, aunque en ciertos casos se debe relativizar la relevancia del acceso al diploma. Hay trayectorias que resultan relevantes para acceder a mejores condiciones de inserción laboral, y que pueden requerir la incorporación de conocimientos pero no su acreditación formal.

Un aspecto a tener en cuenta, que resulta relevante a la hora de medir el éxito de la educación superior en lograr ingresos y egresos, y que no depende sólo de los esfuerzos que hace el sistema de IES, o los niveles educativos previos, es la consideración sobre los capitales culturales de la población que accede al nivel superior, y que, en muchos casos, dan origen a modos particulares de lidiar con la población estudiantil por parte de las instituciones. De este modo, podemos plantear que existen instituciones que deben redoblar esfuerzos para lograr el acceso y la permanencia de poblaciones con escasa experiencia familiar en ese tipo de trayectorias educativas, mientras que en otros casos, la procedencia de los estudiantes de los sectores más elevados de la estructura social, permite éxitos similares o superiores con menores esfuerzos institucionales. 
Los artículos que forman el presente monográfico, retoman parte de estos problemas a través de análisis predominantemente cuantitativos y que exploran la dimensión comparativa, sea de experiencias latinoamericanas entre sí (Argentina y México en el caso del texto de Dalle, Boniolo y Cendejas) o frente a casos europeos (Argentina-España en el texto de Fachelli y Argentina-Finlandia en el de Blanco y Oinonen).

El trabajo "Efectos del origen social familiar en el logro educativo en el nivel superior en Argentina y México. Caminos diferentes, desigualdades similares” se pregunta por el grado de apertura de los sistemas de educación superior a personas provenientes de clases populares o medias bajas en Argentina y México, a partir del análisis comparativo de datos surgidos de ENES-PISAC 2015 y del Censo Nacional de Personas, Hogares y Viviendas 2010 para el primer país, y del módulo Movilidad Social 2016 de INEGI y el Censo de Población y Vivienda 2010 para el segundo.

A partir del análisis de los orígenes familiares y de la región de nacimiento en las desigualdades de oportunidades de graduación universitaria, los autores se preguntan por los cambios en el nivel de apertura del sistema de educación superior.

El foco puesto en las desigualdades regionales, como factor relevante para comprender las distintas posibilidades de acceso a la educación superior en ambos países, vinculando esa diferencia regional con dispares ofertas universitarias, los niveles de entrenamiento escolar previos y los ingresos de las familias, resulta sin dudas un aporte valioso, dada la escasa atención que ha tenido el tema en buena parte de la literatura. La conclusión es que el proceso de desarrollo desequilibrado en ambos países le confiere a la región un papel importante en la posibilidad de acceder a credenciales universitarias.

Por otra parte, el trabajo señala que el nivel educativo del hogar de origen tiene una influencia importante sobre las posibilidades de graduación en ambos casos, incluso que esta variable puede relativizar (aunque no anular) el peso de la clase social de origen.

El trabajo de Sandra Fachelli "El rol de la educación superior en la movilidad ocupacional intergeneracional: análisis comparado entre Argentina y España” se centra en el análisis del papel de la educación superior en la relación origen-destino de clase ocupacional en la movilidad intergeneracional, introduciendo la variable género como dato relevante.

A partir de la constatación de que el mayor nivel educativo promueve formas de ascenso social, la asociación origen-destino baja en los sectores que acceden al nivel educativo superior, lo que permite sostener que el desarrollo de las IES aumenta la fluidez social. 
A partir de ello, Fachelli concluye que en ambos países se encuentra una alta movilidad social ascendente (ligeramente superior en España), pero que la misma es mayor si se toma el universo de las mujeres que presenta menor condicionamiento de origen. También que las condiciones de origen son relevantes en el destino, aunque la variable fundamental es la educación superior de los propios encuestados: a mayor nivel educativo, mejor posición en ambos países.

El trabajo de Blanco y Oinonen "Higher education policies and questions of social (in)equality: cases of Argentina and Finland", busca hacer un análisis comparado entre dos países en apariencia muy diversos, comenzando con un análisis de la evolución de la educación superior en ambos casos en el que se señalan algunos hitos significativos de la constitución de cada uno de los sistemas universitarios.

Los autores demuestran que en el caso de Finlandia, el relativamente reciente proceso de neoliberalización de la sociedad, ha interrumpido parte de los procesos de ascenso social vía educación, aunque la comparación con el caso argentino muestra que los niveles educativos de los padres en el acceso a la educación superior son más determinantes en este segundo país, entre otras cosas por la heterogeneidad de los niveles previos que resultan determinantes para el acceso o no acceso a las IES, lo que los lleva a concluir que, en comparación, las políticas de educación superior en Argentina no lograron éxito en la promoción de la equidad social, incluso si el nivel universitario ofrece gratuidad en sus instituciones públicas.

En síntesis, los tres trabajos que aquí se presentan, giran en torno al problema del aporte del acceso a la educación superior, y en especial a la universitaria, como elemento de ascenso y movilidad social, aunque reconociendo también la existencia de otros factores que juegan un papel significativo en el trayecto origen destino sea individual o intergeneracional.

El reconocimiento del aporte significativo de la educación superior, incluso en países con estructuras económicas y sociales diversas, lleva a cierto consenso sobre la enorme relevancia del sector, de su desarrollo y de la implementación de políticas públicas para su fortalecimiento, en especial cuando los mandatos de las crisis económicas recurrentes, de los apremios fiscales que suelen conocer las economías latinoamericanas, parecen buscar comprometer ese funcionamiento. 
Por esa relevancia, es que las últimas dos Conferencias Regionales de Educación Superior, que se desarrollaron en Cartagena de Indias en 2008 y en Córdoba (Argentina) en 2018 (Didriksson, 2018), han expresado de modo contundente el apoyo de los sistemas universitarios de la región a la consideración de la educación superior como un bien público, y por ello, como un bien que debe ser desmercantilizado, comprometiendo a los estados en su sostenimiento y expansión, en especial porque ante un continente caracterizado históricamente por unas enormes desigualdades estructurales, no hay otra forma de acotar la reproducción de las mismas, que no sea establecer, de diversos modos, políticas inclusivas para que los sectores de menores ingresos, más desfavorecidos, puedan aspirar a los horizontes de posibilidad que generan los niveles educativos superiores.

\section{Bibliografía}

DEL VAlLE, D. MONTERO, V. MAURO, S. (2017). El derecho a la universidad en perspectiva regional, Buenos Aires, CLACSO-IEC.

BLANCO, C. OINONEN, E. (2019). "Higher education policies and questions of social (in)equality: cases of Argentina and Finland”, Revista de educación y derecho,19,1-22.

DALLE, P BONIOLO, P. NAVARRO CENDEJAS, J. (2019). "Efectos del origen social familiar en el logro educativo en el nivel superior en Argentina y México. Caminos diferentes, desigualdades similares", Revista de educación y derecho, 19. 1-23.

DIDRIKSSON, A. (2018). "De Cartagena a Córdoba: balance y perspectivas de la educación superior en América Latina y el Caribe”, En: Guajardo Henríquez, P. (ed), Estudios retrospectivos y proyecciones, UNESCO-IESALC y UNC, 2018. Recuperado de: http://www.cres2018.org/uploads/Estudios\%20retrospectivosIMPRENTA31mayo.pdf

FACHELLI, S. (2019). "El rol de la educación superior en la movilidad ocupacional intergeneracional: análisis comparado entre Argentina y España", Revista de educación y derecho, 19, 1-26.

WORLD BANK. (2017). At a Crossroad. Higher education in Latin America and the Caribbean, Washington. Recuperado de: https://openknowledge.worldbank.org/handle/10986/26489 